\title{
Offshore Country Selection Risk Management Model: Systematic Literature Review Protocol
}

\author{
Nasir Rashid ${ }^{1}$, Siffat Ullah Khan ${ }^{1}$ \\ ${ }^{I}$ Software Engineering Research Group (SERG_UOM) Department of Computer Science \& I.T, University of \\ Malakand, Khyber Pakhtunkhwa, Pakistan.
}

\begin{abstract}
CONTEXT - Global software development (GSD) is a modern business strategy for the development of high quality software. The main reason for selecting GSD or offshore outsourcing technique include faster development, reduced cost and access to large pool of skilled manpower. In today's world of engineering development, most of the outsourced projects suffer from unwanted threats called risks that can badly affect the cost, quality and schedule of the critical projects. Appropriate measure should be planned for the successful offshore development outsourcing projects.

OBJECTIVE - The objective of this protocol is to identify the potential risks that are considered to be critical and having high probability of occurrence concerning offshore country selection for software outsourcing and that will assist the clients organization in selection of suitable offshore country worldwide.

METHOD - These potential risks will be identified using a Systematic Literature Review (SLR). SLR is a technique of identifying, evaluating and interpreting all the relevant research that is available to a particular research question or topic of interest and has different types of scientific values that differentiate it from ordinary literature surveys and reviews.

EXPECTED OUTCOME - We have been developed SLR protocol for offshore country selection risk management model (OCSRMM) and now in the implementation phase. The expected outcomes of SLR review will be the identification and analysis of potential risks to be addressed by client organizations for appropriate management and mitigation of offshore software development contracts. Our ultimate goal of this research is to develop OCSRMM and to design the structured plan for the development of this model.
\end{abstract}

Keywords - Global Software Development, Systematic Literature Review, offshore software development

\section{INTRODUCTION}

Software development outsourcing is a contractual business relationship between client and vendor organizations in which a client(s) outsources out all or some part of its software development activities to a vendor(s) organization. The vendor organization in turn provides agreed services for certain amount of remuneration [1]. Offshore outsourcing also known as far shore outsourcing is like an international trade through which the nations get considerable benefits [2]. The main reason for choosing this methodology is due to its cost effectiveness and access to leading-edge technology, huge pool of skilled labor, high quality standard software development and round the clock services [3]. The availability of these skilled resources and effective costs are the primary motivators for software businesses to move to software development activities offshore [4]. Software development outsourcing is becoming very complex, difficult and challenging technique in the context of software project management due to the probability of unwanted threats called risks that can have a negative impact on outsourcing project $[5,6,7]$. The risks that mostly occur in software outsourcing are much different than the risks of local software development. Even a very small risk becomes serious catastrophic risk in software outsourcing development $[8,9]$. Software risks should be identified controlled and monitor from the start phase of software outsourcing management life cycle [10].

To avoid threats and to reap opportunities in software outsourcing a client organization needs to explore and identify the possible risks and plan to mitigate and manage these for the effective standard software development [11]. There are a lot number of risks as identified in [12] that need to be addressed by client organizations for outsourcing success. One of the major risks, which is responsible for controlling and monitoring the quality of a product, is the criteria for the distribution of software development activities to offshore countries. So the decision of country selection and its company's evaluation around the world is a time consuming and difficult problem to be solved. However, based on the expertise, relationship, culture, productivity, skilled developers, ease of communication, languages spoken, distance and coordination, manager of a client organization can decide [13].

Based on the risk identification and management principle proposed in [14] and the framework of risks associated with offshore outsourcing software development [15], it is very clear that in offshore outsourcing software development, risks identification and management is conducted in various phases, in which the major phase is concerned with the selection of suitable offshore country based on the nature of software development 
activities. In the context of OSDO, however, client organization without proper knowledge could encounter miserable performance. OCSRMM has outlined various criteria for offshore country selection that must be followed for successful offshore outsourcing.

The main objective of this research is to gain an in-depth and more thoroughly understanding of the potential risks in the contexts of OCS from client's organization perspective and to develop a plan for the management of identified risks.

\section{BACKGROUND}

It is the evidence that the world has changed the trend in dealing with software development process. Traditional software development was mostly confined to in-house software development, now the process has been moved to global software development, where whole software process is contracted out to different offshore countries around the world [16]. The reasons to adopt outsourcing methodology is to achieve quality, availability of large pool of expert developers, to be able to do round -the-clock development, and huge saving in labor cost in developing countries [17]. Despite the fact that software outsourcing is widely being used, however, the client organizations deal with complex, difficult risks and challenges. Major risks categories can be offshore strategic, country selection, provider selection, contact negotiation, project implementation, commissioning and contact negotiations [18]. We extended our research on risks identification and management in offshore country selection for successful outsourcing in the context of offshore software outsourcing from client's perspective. Software outsourcing Risk is the net negative impact of the exercise of vulnerability, considering both the probability and the impact of its occurrence on outsourcing projects. Risk management is the process of identification, assessment and taking steps to reduce the risks to an acceptable level [19].

OCSRMM provides a foundation for the development of an effective risk management plan for identifying and managing the risks concerning offshore country selection in the context of software outsourcing. A number of researchers have tried to address some of the risks in offshore country selection process for software outsourcing from client's organization perspective.

Selecting an appropriate offshore country is a critical step for successful offshore outsourcing [19]. According to the study the authors have mentioned in their findings of the study that offshore country selection plays an important role in offshore software outsourcing. Major risks in offshore country selection occur due to the problems related with the possibility of shifting local political, regulatory and economic conditions of the developing country. The risk needs better political and economic knowledge of the developing country for successful outsourcing [20].

Country political system can also badly affect the offshore outsourcing in selection of suitable country. Their findings reveal that for example political condition of India/Pakistan on Kashmir dispute had created an intensified alertness of political risks for outsourcing to India [21].Technology transfers, privacy laws, intellectual property and copyrights and Transborder data flows can seriously affect the client's decision regarding offshore country selection that can lead failure of software outsourcing to software [22].

The difference of culture at the country level may have negative impact upon the offshore country selection [23]. Similarly at the vendor's organization level there are also different culture and real practices such as norms and business moral that are dominant in appropriate country selection from client's perspective [24]. Offshore country selection decision may be affected due to a substandard telecommunications infrastructure [25]. Distribution of software development activities to any offshore country having substandard telecom infrastructure can adversely affect the outsourcing paradigm. Client organization must be well updated about the country telecom infrastructure which is considered as a foundation for other strategies [26].

There is a serious risk involved in offshore country selection, which deals with legal frameworks for data security and intellectual property rights are not well defined in the offshore country. The stated risk has a negative effect on the client's expectation of software projects related to client's data and communication secrecy [27]. The macroeconomic risk like exchange rate fluctuations of offshore developer country greatly reduces its probability of being selected as an outsourcing country candidate. Frequent change in currency rates creates an illusion for the client to bargain a software project. Client must update its database of currency rates of offshore countries for better selection [28].

According to [29], political and economic stability is a key factor that must be considered by the client in the context of offshore country selection for software development outsourcing. Research conducted by [30] argues that educational system of an offshore developer country has an influence effect on its selection for outsourcing. A country can be evaluated for its literacy rate which has a positive role in the growth of outsourcing industry. The availability of highly skilled human resources with in a country is in essential factor that should be considered when selecting an offshore country for software outsourcing from client's perspective. A country labor force must have significant software development skills [31].

This research will supplement the work previously carried out in these studies. A number of research studies, as mentioned above, have explored the critical factors that should be considered for offshore country 
selection in the context of software outsourcing from client's perspective. However, Systematic Literature Review (SLR) [33] methodology has not been adopted in this regard for the identification of risks and their management in the process of offshore country selection and its evaluation from client's organization perspective.

\section{SYSTEMATIC LITERATURE REVIEW PROTOCOL}

Our research paper contributes to design a unique SLR protocol for offshore country selection risks management model (OCSRMM) in offshore software outsourcing from clients' perspective by using the guideline of Kitchenham [31]. There are three main stages of systematic literature review i.e planning the review, conducting the review and reporting the review [19]. In this paper we have exercised the planning phase that will produce the systematic review protocol to generate the aim and procedure for the review. According to [32] the pre-defined protocol definition reduces the possibility of researcher bias. While designing our OCSRMM protocol, we have studied various standard protocols following the SLR for guidance. Systematic literature review process is depicted in figure 1.

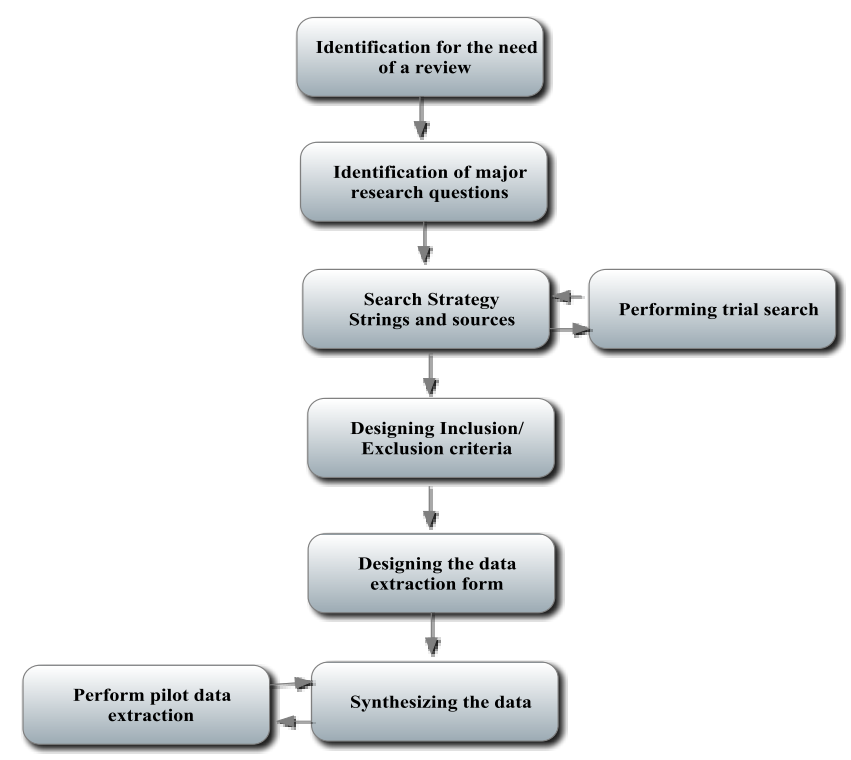

Figure 1: Systematic Literature Review Process

\section{RESEARCH QUESTIONS}

There are four research questions that have motivated this research study.

RQ1: What are the factors to be considered by the client organization for selecting suitable offshore country for successful software development outsourcing?

RQ2: What are the risks to be avoided as identified in literature, faced by client's organization in offshore country selection in the context of offshore software outsourcing?

RQ3: What are the risks, as identified in the real world practices, faced by client's organization in offshore country selection in the context of successful offshore software outsourcing?

RQ 4: What are the practices for risks management/mitigation or risks avoidance of the identified risks faced by client's organization in offshore country selection in the context of offshore software development outsourcing?

\subsection{CONSTRUCTING THE SEARCH TERM} questions.

The following details will help us in designing a search term related to the above mentioned research

Population: Offshore country and software outsourcing clients and vendors.

Intervention: Risks, factors, criteria, country selection, risks management, risks mitigation.

Outcomes of relevance: Positive impact on clients in the country selection process, factors for offshore country selection, risks in offshore country selection, risks mitigation/management model.

Experimental Design: Empirical studies, systematic literature review, theoretical studies, case studies, experts' opinions.

An example of the Research Question containing the above details is:

RQ1:

[What Criteria/factors] -"INTERVENTION"

are considered by the 
Offshore country selection risk management model: Systematic literature Review Protocol

[Software outsourcing clients]-------------------"POPULATION"

in selection of suitable offshore country

[for successful outsourcing] ----_ouTCOMES OF RELEVANCE"

RQ2:

[What are the risks] ---

to be avoided by

[software outsourcing clients]

in selection of suitable offshore in order to design

[risk management model for successful of outsourcing] ----------."OUTCOMES OF RELEVANCE”

\section{SEARCH STRATEGIES}

\subsection{TRIAL SEARCH}

A trial search was conducted using the following search string on cite seer digital library.

((“Software outsourcing risk" OR "outsourcing risk" OR "IT outsourcing risk" OR "IT/IS offshore outsourcing risk" OR "outsourcing Risk mitigation" OR "outsourcing Risk management" OR "global software outsourcing risk") AND (issues OR Problems OR factors OR factor OR criteria OR barriers ) AND (client OR "client organization" OR customer))

The papers retrieved through this search string will be used as a guide for the development and validation of the major search terms.

\subsection{STEPS FOR IDENTIFYING THE SEARCH TERMS}

The following search strategy is used for the construction of search terms.

a. Use the Research Questions for the derivation of major terms, by identifying population, intervention and outcome.

b. For these major terms, find the alternative spellings and synonyms;

c. Verify the key words in any relevant paper;

d. Use of Boolean Operators for conjunction if the database allows, in such a way, to use 'OR' operator for the concatenation of alternative spellings and synonyms whereas 'AND' for the concatenation of major terms.

e. Integrate the search strategy into a summarize form; if required.

Results for a)

RQ1: Offshore software outsourcing, criteria, factors, offshore country selection, successful outsourcing.

RQ2: Offshore software outsourcing, risks, barriers, offshore country selection, successful outsourcing.

Results for $b$ )

RQ 1: Software outsourcing: ("software outsourcing" OR "information systems outsourcing" OR "information technology outsourcing" OR "IS outsourcing" OR "IT outsourcing"

OR "CBIS outsourcing" OR "computer-based information systems outsourcing" OR "software facility management" OR "software contracting-out")

Criteria: (factors OR drivers OR motivators OR elements OR characteristics OR parameters)

Offshore country: ("Offshore country "OR "far shore country")

Selection: (selection OR choosing OR analyzing OR assessing OR evaluating)

Client: (client OR clients OR client organization OR outsourcer OR buyer OR customer OR user OR consumer) RQ 2: Software outsourcing: ("software outsourcing" OR "information systems outsourcing" OR "information technology outsourcing" OR "IS outsourcing" OR "IT outsourcing" OR "CBIS outsourcing" OR "computerbased information systems outsourcing" OR "software facility management" OR "software contracting-out")

Risk: (risk OR risks OR issues OR threat OR "potential threats" OR "risk mitigation" OR "risks management" OR "risks avoidance")

Selection: (selection OR choosing OR analyzing OR assessment OR evaluating)

Clients: (clients OR client OR outsourcer OR buyer OR customer OR user OR consumer)

Results for c)

Software outsourcing, Offshore outsourcing, IS/IT outsourcing, global software outsourcing, global software development, country selection, suitable country selection, vendor's country selection, offshore country selection risk, issues, critical factors, risks, barriers, problems, potential threats, risks management, risks mitigation, risks avoidance, client, client organization, customer, outsourcer.

Results for d)

RQ 1: (("offshore software outsourcing" OR " information system outsourcing" OR "Information technology outsourcing" OR "IS outsourcing" OR "IT outsourcing" OR "CBIS outsourcing" OR " computer-based information system outsourcing" OR " software contracting-out") AND ( Criteria OR factors OR reasons ) AND ("Offshore country" OR "far shore country") AND (selection OR choosing OR analyzing OR assessment OR evaluating) AND (clients OR client OR outsourcer OR buyer OR customer OR user OR consumer)) 
RQ2: (("offshore software outsourcing" OR " information system outsourcing" OR " Information technology outsourcing" OR "IS outsourcing" OR "IT outsourcing" OR "CBIS outsourcing" OR " computer-based information system outsourcing" OR " software contracting-out") AND (risk OR risks OR issues OR threat OR "potential threats" OR "risk mitigation" OR "risks management" OR "risks avoidance") AND (selection OR choosing OR analyzing OR assessment OR evaluating) AND (clients OR client OR outsourcer OR buyer OR customer OR user OR consumer))

\subsection{SEARCH TERM BREAK UP}

We will use the search strings RQ1 and RQ2 as defined in (d) as our major search terms.

Some of the databases/ libraries searching mechanism is designed in a such a way that it don't permit lengthy strings, therefore large search strings are split according to the syntax of digital library into small substrings. These small strings are then searched separately and the final retrieved results are summarized by removing the redundancy. It should be kept in mind that while using IEEEXplore digital library, the prior mentioned search string will be used such that it should be put in large rectangular text-boxes mentioned in advanced search. The ' $\mathrm{e}$ ' rule that integrates the best related results must be followed in case using Google Scholar. The substring for the defined research question RQ1 and RQ2 are given below.

Each search term in the research question is divided into sub terms accordingly.

Search String 1: (("offshore software outsourcing" OR " information system outsourcing) AND ( Criteria OR factors OR reasons ) AND ("Offshore country" OR "far shore country") AND (selection OR choosing) AND (clients OR outsourcer ))

Search String 2: (("Information technology outsourcing" OR "IS outsourcing" OR "IT outsourcing") AND ( Criteria OR factors OR reasons ) AND ("Offshore country" OR "farshore country") AND (analysing OR assesment OR evaluating) AND (Client organization OR buyer OR customer OR user ))

Search String 3: (("CBIS outsourcing "OR "software contracting-out") AND ("Offshore country selection "OR "far shore country selection") AND (risks OR issues OR threat) AND (outsourcer OR customer))

Search String 4: (("offshore software outsourcing "OR "information system outsourcing "OR "software contracting-out") AND ("Offshore country selection "OR "far shore country selection") AND (issues OR risks OR risks management) AND (clients OR outsourcer OR customer OR Client organization))

Search String 5: (("offshore software outsourcing "OR "contracting-out") AND ("Offshore country selection "OR "far shore country selection ") AND (risks OR "risks management "OR "risks avoidance") AND (client organization OR outsourcer OR customer))

\subsection{RESOURCES TO BE SEARCHED \\ - IEEE Xplore (http://ieeexplore.ieee.org/Xplore/guesthome.jsp) \\ - ACM Portal (http://dl.acm.org) \\ - $\quad$ ScienceDirect (www.sciencedirect.com) \\ - $\quad$ Cite Seer Digital Library (www.citeseer.ist.psu.edu) \\ - $\quad$ SpringerLink (www.springerlink.com) \\ - Google Scholar (www.scholar.google.com)}

The search was conducted in the above mentioned libraries and we found the results. It should be noted that we have used the search strings mentioned in 5.3

\subsection{SEARCH CONSTRAINTS AND VALIDATION}

Our searching for the related trial search string in the different published paper doesn't have any constraints like date boundaries etc. The above mentioned digital libraries will be searched for the trial string; (("Software outsourcing risk" OR "outsourcing risk" OR "IT outsourcing risk" OR "IT/IS offshore outsourcing risk" OR "outsourcing Risk mitigation" OR "outsourcing Risk management" OR "global software outsourcing risk") AND (issues OR Problems OR factors OR factor OR criteria OR barriers ) AND (client OR "client organization" OR customer))

\subsection{SEARCh Documentation}

Retrieved papers will be stored in separate table with maintaining the following information (Name of Database, Search Strategy, Search Phase, Date of Search, Years Covered, No of Publication Found Initial Selection Decision, Final Selection Decision. 
Table 1: Documentation of Trial Search String

\begin{tabular}{|c|c|c|c|c|c|}
\hline Name of DB & Search Strategy & $\begin{array}{l}\text { Search } \\
\text { String } \\
\text { No. }\end{array}$ & $\begin{array}{l}\begin{array}{l}\text { Date } \\
\text { of } \\
\text { search }\end{array} \\
\end{array}$ & $\begin{array}{l}\text { Years } \\
\text { covered } \\
\text { by } \\
\text { search }\end{array}$ & $\begin{array}{l}\text { Number of } \\
\text { publications } \\
\text { found }\end{array}$ \\
\hline IEEE Xplore & \multirow{3}{*}{$\begin{array}{l}\text { ((“Software outsourcing risk" OR } \\
\text { "outsourcing risk” OR "IT } \\
\text { outsourcing risk" OR "IT/IS } \\
\text { offshore outsourcing risk" OR } \\
\text { "outsourcing Risk mitigation" OR } \\
\text { "outsourcing Risk management" } \\
\text { OR "global software outsourcing } \\
\text { risk") AND (issues OR Problems } \\
\text { OR factors OR factor OR criteria } \\
\text { OR barriers ) AND (client OR } \\
\text { "client organization" OR } \\
\text { customer)) }\end{array}$} & $\begin{array}{l}\text { Trial } \\
\text { Search }\end{array}$ & $\begin{array}{l}20-07- \\
2012\end{array}$ & All & 60 \\
\hline ACM & & $\begin{array}{l}\text { Trial } \\
\text { Search }\end{array}$ & $\begin{array}{l}20-07- \\
2012\end{array}$ & All & 14 \\
\hline $\begin{array}{l}\text { Google } \\
\text { Scholar }\end{array}$ & & $\begin{array}{l}\text { Trial } \\
\text { Search }\end{array}$ & $\begin{array}{l}20-07- \\
2012\end{array}$ & All & 1230 \\
\hline
\end{tabular}

\subsection{MANAGEMENT OF SEARCH RESULT}

The records of all the candidate papers from retrieved from various digital libraries are kept in a directory on University of Malakand Server. Records of each digital library will be stored in a separate directory, where each page is saved as.html page. Table 2 depicts the management of results.

Table 2: Search Result Management

\begin{tabular}{|l|l|l|l|}
\hline S. No & Tracing No. & Database & \multicolumn{1}{c|}{ Paper Title } \\
\hline $\mathbf{1}$ & IEEE-1 & IEEEXplore & $\begin{array}{l}\text { Influence of culture on risks in offshore outsourcing of } \\
\text { software projects: A quantitative study on mum effect }\end{array}$ \\
\hline $\mathbf{2}$ & ACM-2 & ACM & $\begin{array}{l}\text { Barriers in the selection of offshore software development } \\
\text { outsourcing vendors: An exploratory study using a } \\
\text { systematic literature review. }\end{array}$ \\
\hline
\end{tabular}

\section{Publication Selection}

This section defines the criteria for inclusion, exclusion and the selection of primary sources. We want only those publications to be included which are relevant to the research questions. The focus of this proposed protocol is majorly on the selection of suitable offshore country selection and the risks involved in this step for successful outsourcing activity. After the identification of the risks involved, our aim is to develop risk mitigation and management model for successful outsourcing. The process of document selection is shown in Figure 2.

\subsection{INCLUSION CRITERIA}

The criteria described below has been designed for the purpose to define which part of literature (papers, technical reports, or 'grey literature') found by the search term will be used for data extraction process. Our consideration will be only for offshore outsourcing. Principles for the selection of the relevant papers are as follows:

- Studies that describe client's ability for offshore outsourcing.

- Studies that define the factors to be considered for the selection of offshore country for outsourcing.

- Studies that describe the criteria for the selection of offshore country for successful software outsourcing.

- Studies that describe the relationship between software outsourcer and vendor.

- Studies that describe criteria for a successful software outsourcing contract.

- Studies that describe motivation for offshore software outsourcing.

- Studies that describe the issues involved in software outsourcing management.

- Studies that describe critical risks involeved in the selection of suitable offshore country for software outsourcing.

- Studies that describe mitigation for the risks involved in offshore software outsourcing.

- Include papers written in English language.

- Include paper whose title is related to offshore coountry selection for software outsourcing.

- Include paper that contain keywords that match with those defined in the search strings. 


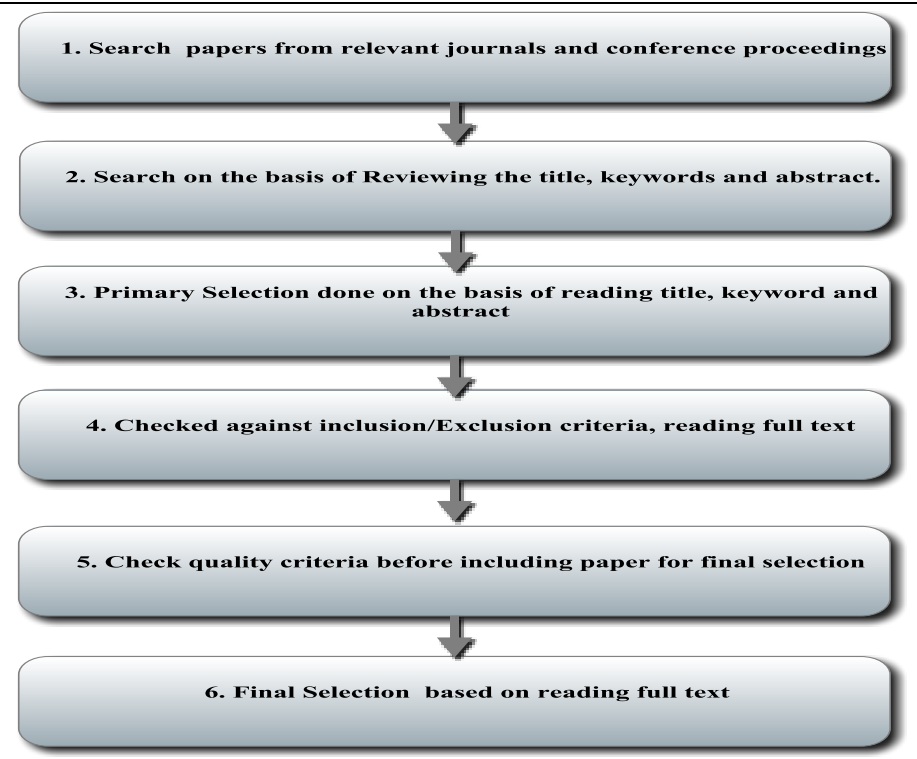

Figure 2: Publication Selection Process

\subsection{EXCLUSION CRITERIA}

This section explicitly defines the exclusion criteria that have been designed in order to decide the exclusion of literature (papers, technical reports, or 'grey literature'), found through search string.

The criteria are listed as follow:

- Studies that do not match with research questions.

- Studies that have no relevancy with client and vendors in offshore software outsourcing.

- Studies that do not describe the factors or criteria for the selection of suitable offshore country for successful outsourcing..

- Studies that do not describe the risks involved in offshore county selection in outsourcing.

- Studies that do not explain any mitigation or voidance plan for the risks identified in outsourcing.

- Exclude all duplicate papers.

\subsection{SELECTING PRIMARY SOURCES}

Papers will be selected initially after reviewing the title, keywords and abstract of the retrieved papers. The purpose of this finding is to exclude all the irrelevant data.

This source of study has been carried out in order to check the results against the inclusion/exclusion criteria after complete review of the articles. In order to avoid any uncertainty regarding the primary study, a secondary reviewer has been requested to check the selected data according to the inclusion/exclusion criteria defined for selection. Record of the primary study data is properly maintained and checked regularly with the aforementioned criteria.

\section{PUbliCATION QUALITY ASSESMENT}

Quality is measured after the final selection of publications. The quality will be assessed in parallel at the time of data extraction. Quality assessment will be carried out on the basis of the following questions:

- Is it clear how the offshore country screening was performed?

- Is it clear how the criteria/factors for the selection of offshore country for successful software outsourcing were identified in the outsourcing business?

- Is it clear how the risks involved in the selection of offshore country were identified in outsourcing business?

- Is it clear that what types of risks are involved in offshore software outsourcing ?

- Is it clear that no expert opinion taken?

The above mentioned factors will be marked as 'YES' or 'NO' or 'NA'. 


\section{DATA EXTRACTION STRATEGY}

\subsection{PRIMARY STUDY DATA}

Data is collected from the selected publication through this study that is focused to satisfy the research questions. The following data will be extracted from each of the selected publication.

Publication details: (Title, Author(s), Journal/Conference title, etc.) Data, that addresses the research questions. The following data will be extracted that address the research questions:

RQ1: Background information, Factors or criteria: factors or criteria that are copnsiderd when selecting an appropriate country for successful offshore sotware outsourcing activity.

RQ2: Background information, risks: risks that are involved in selection of suitable offshore country for successful offshore software outsourcing projects.

RQ3: Background information, Practices: practice or solution or advice that will be identified in the literature for the proper mitiogation or avoidance of the risks identified for successful offshore software outsourcing projects. Table 3 depicts the data to be captured in the data extraction process.

\subsection{DATA EXTRACTION PROCESS}

The primary review will be carried out by a single researcher, who will be alone responsible for data extraction process. In case of any confusion regarding the data extraction, secondary reviewer will be there for proper guidance.

Inter-rater reliability test will be conducted by the primary reviewer after the data extraction process. The secondary reviewer will select randomly from the already chosen publications. The secondary reviewer will extract independently from the randomly selected publication and the result will be compared with the finding of the primary reviewer.

\subsection{DATA STORAGE}

The summarized data for each selected publication will be kept as SPSS document and will be stored on a local drive at University of Malakand data server.

Table 3: Data Extraction from Candidate Papers

\begin{tabular}{|c|}
\hline Data To Be Extracted \\
\hline $\begin{array}{l}\text { Date of review } \\
\text { Title } \\
\text { Authors } \\
\text { Reference } \\
\text { Database } \\
\text { Methodology (interview, case study, report, survey, etc) } \\
\text { Sample Population } \\
\text { Publication Quality Description } \\
\text { Organisation Type (Software house, University, Research } \\
\text { institute etc) } \\
\text { - } \text { Company size (small, medium, large) } \\
\text { Country / location of the analysis } \\
\text { Year } \\
\text { Factors or Criteria: factors or criteria that is considered when selecting a suitable } \\
\text { - } \\
\text { - } \quad \text { Risks: Risks that are involved in software outsourcing and has a bad effect on the } \\
\text { - } \quad \text { Real world practices as identified in the literature for the avoidance of these risks } \\
\text { selection process of offshore country for successful outsourcing activity. } \\
\text { for successfuloffshore software development }\end{array}$ \\
\hline
\end{tabular}

\section{DATA SYNTHESIS}

We will categories the data synthesis in three parts according to the number of questions. For the first research question, the data will be synthesized by creating separate tables, such that any background information is placed in table one, while the other table will contain the data classifying factors or criteria. For the 2nd research question, the data will be synthesized by creating a table such that, any background information is placed in one table, whereas the other table will include the data about the risks identified. For the final research question, the data will be synthesized by creating a table such that, any background information is placed in one table, whereas the other table will include the data of real world practices. 


\section{$X$ VALIDATION OF REVIEW PROTOCOL}

The designed protocol will be submitted to secondary reviewer Dr. Siffat Ullah Khan and Software Engineering Group SERG of UOM for suggestion and improvement. After updating, it will then be presented to the software engineering group at University of Malakand for further suggestions and improvements if any. Finally it will be published as technical report in any well-known expected journal.

First reviewer comments: The protocol was presented to the SERG_UOM group of on 14th-June-2012 and they have approved and validated it.

a. second reviewer comments: The protocol is reviewed by the SERG_UOM group member Muhammad Salam and Abdul Wahid and modified according to the suggestions

b. Third reviewer comments: The supervisor has reviewed the OCSRMM Protocol and enhanced the protocol.

\section{DIVERGENCES}

In case of any variance from the proposed protocol development, which may occur during the course of study, we will record the change in a new Appendix to this document.

\section{LIMITATION}

- Some of the digital libraries do not give correct result related to the research questions. e.g CiteSeerX and science Direct.

- In order to get efficient result from google scholar the integrated rule 'e' is used.

- For finding the real world practices related to the risks and factors in the involved in the selection of suitable offshore country for software outsourcing in the existing literature a new research question third (RQ3) is included.

- Research (RQ4) will be used to find the real world practices using empirical study (questionnaire survey), will be conducted.

\section{ACKNOWLEDGEMENTS}

We are thankful to software engineering group (SERG_UOM), University of Malakand, the reviewer and my fellows for their assistance and suggestions in the review process.

\section{REFERENCES}

[1] S. U. Khan, M. Niazi, and R. Ahmad, "Barriers in the Selection of Offshore Software Development Outsourcing Vendors: An Exploratory Study using a Systematic Literature Review," Information and Software Technology,(Elsevier), doi: 10.1016/j.infsof.2010.08.003, 2010.

[2] B. Kitchenham and C. Charters, "Guidelines for performing Systematic Literature Reviews in Software Engineering, Keele University and Durham University Joint Report," EBSE 2007-001, 2007.

[3] H. S. Kehal and V. P. Singh, Outsourcing and offshoring in the 21 st Century: A Socio-Economic Perspective.

[4] J. K. HALVEY and B. M. MELBY, INFORMATION TECHNOLOGY OUTSOURCING TRANSACTIONS PROCESS, STRATEGIES, AND CONTRACTS, 2ND EDITION ed: John Wiley \& Sons, Inc., Hoboken, New Jersey.Published simultaneously in Canada.

[5] G. Wang, Z. Jiang, Z. Li, and W. Liu, " Supplier selection and order splitting in multiple-sourcing inventory systems," Frontiers of Mechanical Engineering in China, vol. 3, pp. 23-27.

[6] R. Sharma, S. Apoorva, V. Madireddy, and V. Jain, "Best Practices for Communication between Client and Vendor in IT Outsourcing Projects," Journal of Information, Information Technology, and Organizations, vol. 3, 2008.

[7] P. Kanawattanachai and Y. Yoo, "Dynamic Nature of Trust in Virtual Teams," The Journal of Strategic Information Systems, vol. 11 , pp. 187-213, 2002.

[8] O. d. Gaudemar, "Multi-sourcing: benefits and challenges," vol. 2011

[9] "Egham, UK, August 27, 2009 - Gartner, Inc Three Pitfalls of Multisourcing," vol. 2011,27 August 2009.

[10] v. b. kartha, "Multi-Sourcing from Best of Breed Providers:Perspectives for BPO," vol. 2011, January 2007.

[11] P. Kanawattanachai and Y. Yoo, "Dynamic Nature of Trust in Virtual Teams," Sprouts: Working Papers on Information Systems, vol. 2, 2002.

[12] ShitaoYanga, JianYangb, and L. Abdel-Malek, "Sourcing with random yields and stochastic demand: A newsvendor approach," Computers \& Operations Research, vol. 34, pp. 3682 - 3690, 2007.

[13] N. Levina and N. Su, "Global Multisourcing Strategy: TheEmergence of a Supplier Portfolio in Services Offshoring," Decision Sciences, vol. Volume 39 Number 3, pp. 541-570, August 2008.

[14] B. Kitchenham, "Procedures for Performing Systematic Reviews," Keele University Technical ReportTR/SE0401, 2004.

[15] M. J. Power, K. C. Desouza, and C. Bonifazi, The Outsourcing Handbook How to implement a successful outsourcing process: First published in Great Britain and the United States in 2006 by Kogan Page Limited.

[16] M. Ali-Babar, J. Verner, and P. Nguyen, "Establishing and maintaining trust in software outsourcing relationships: An empirical investigation," The Journal of Systems and Software, vol. 80, pp. 1438-1449, 2007.

[17] S. U. Khan and M. Niazi, "Systematic Literature Review Protocol for Software Outsourcing Vendors Readiness Model (SOVRM), Technical Report: TR/08-01, ISSN: 1353-7776, School of Computing and Maths, Keele University, UK," 2008.

[18] M. J. Gallivan and W. Oh, "Analyzing IT Outsourcing Relationships as Alliances among Multiple Clients and Vendors," presented at Proceedings of the 32nd Hawaii international Conference on System Sciences, Hawaii, USA, 1999.

[19] V. Imsland, "The Role of Trust in Global Software Outsourcing Relationships," in Department of Informatics: UNIVERSITY OF OSLO, 30th July 2003.

[20] Ramingwong, S.R.a.L., The Paradoxical Relationships of risks and Benefits in Offshore Out-sourcing of Software Projects. The Open Software Engi-neering Journal, 2009. 3(2): p. 35-38. 
[21] Rao, M.T., Key Issues for Global it Sourcing:Country and Individual Factors. Information Systems Management, 2004. 21(3): p. $16-25$.

[22] Thibodeau, P.a.T.H., Surviving Offshore Cutbacks. 2003, Computer world.

[23] Nahar, N., T. Käkölä, and N. Huda. Software Production in Developing and Emerging Countries through International outsourcing. in 7th International Working Conference of IFIP WG 9.4. 2002. Bangalore, India: Information and Communication Technologies and Development: New Opportunities, Perspectives \& Challenges.

[24] Ramarapu, N., M.J. Parzinger, and A.A. Lado, Issues in Foreign Outsourcing.” Information Systems Management. 1997. 14(2): p. $27-31$

[25] Prikladnicki, R., J.L.N. Audy, and R. Evaristo, Global software development in practice lessons learned. Software Process: Improvement and Practice, 2003. 8(4): p. 267-281.

[26] Jennex, M.E.a.O.A., Success Factors for Offshore System Development. Journal of Information Technology Cases and Applications, 2003. 5(3): p. 12-31.

[27] Aron, R., Clemons, E. K. and Reddi, S, Just right outsourcing: understanding and managing risk. Journal of Management Information Systems 2005. 5(2): p. 87-92.

[28] Schmidt, R., Lyytinen, K., Keil, M. and Cule, P, Identifying software project risks: An international Delphi study. Journal of Management Information Systems, 2006. 7(4): p. 5-36.

[29] Beulen, E., Fenema, P. V. and Currie, W, From application outsourcing to infrastructure management: extending the off-shore outsourcing service portfolio. European ManagementJournal 2005. 12(4): p. 145-152.

[30] Aubert, B.A., Party, M. and Rivard, S, A framework for information technology outsourcing risk management. . The Data Base for Advances in Information Systems 2006. 13(2): p. 122-127.

[31] Kitchenham, B., Guidelines for performing Systematic Literature Reviews in Software Engineering, EBSE-Technical-Report. 2007.

[32] Niazi, M., An empirical study for the improvement of requirements engineering process, in The 17th International Conference on Software Engineering and Knowledge Engineering. 2005: Taipei, Taiwan, Republic of China.

[33] Khan, S.U., PhD thesis. 2011, Keele University, UK. 